\title{
EL CONTROL DE CONSTITUCIONALIDAD DE LAS REFORMAS CONSTITUCIONALES. ¿UN OXIMORÓN CONSTITUCIONAL? COMENTARIO AL ATC 9/2012
}

\author{
IGNACIO VILLAVERDE MENÉNDEZ \\ Catedrático de Derecho Constitucional \\ Universidad de Oviedo
}
SUMARIO.-
I. Consideraciones generales
II. El auto. Un buen planteamiento para un de- senlace decepcionante
III. Conceptos y palabras. El oxímoron del control del control de constitucionalidad de la reforma constitucional
IV. Algunas cuestiones pendientes

\section{CONSIDERACIONES GENERALES}

Hablaba Javier Pardo en su comentario al artículo 27 de la Ley Orgánica 2/1979, de 3 de octubre, del Tribunal Constitucional (en adelante, LOTC) de que la «impugnabilidad ante el Tribunal Constitucional de las denominadas leyes de reforma de la Constitución» estaba aún por resolver y se estaba a la espera de que «nuestro Juez constitucional tenga la oportunidad de emitir algún pronunciamiento al respecto» ${ }^{1}$. Pues bien, ese pronunciamiento ha llegado treinta y dos años después del inicio de las actividades del Tribunal con el ATC 9/2012, objeto de este comentario.

Ha sido éste un asunto, el relativo al control de constitucionalidad de las reformas constitucionales, que no ha merecido en nuestra doctrina un análisis detenido ni inten-

1 PARDO FALCÓN, J, Comentario al artículo 27 LOTC, en «Comentarios a la Ley Orgánica del Tribunal Constitucional», REQUEJO PAGÉS, JL (coord.), Tribunal Constitucional/Boletín Oficial del Estado, Madrid, 2001, pág. 386. 
so. Y las pocas opiniones que se han oído han sido muy dispares en sus juicios. Parece que hay una cierta idea mayoritaria según la cual las «leyes de reforma constitucional», como tales leyes, pueden ser objeto de control de constitucionalidad en lo que respecta a su formalidad procedimental, pero no a su contenido. Pocas han sido las voces que han sido rotundas en su rechazo a tal control, sea sobre el fondo, lo sea sobre el procedimiento ${ }^{2}$. A este debate se volverá en las páginas que siguen.

No crea el lector que en este Auto de TC (en adelante, ATC) va a encontrar soluciones o al menos argumentos sobre el asunto. El TC ha eludido las cuestiones capitales de fondo que el objeto del recurso parecía plantear. En efecto, este ATC, el primero en la historia constitucional española que se enfrenta a la delicada cuestión sobre el control jurisdiccional de las reformas constitucionales, ha soslayado responder a la principal de las cuestiones que semejante asunto le planteaba en primer término como cuestión previa, a pesar de que no fuese esa la cuestión principal suscitada en la demanda del recurso de amparo, ¿posee la competencia para realizar tal control de constitucionalidad? Y si la posee, ¿en qué términos?

Probablemente así deba ser porque este ATC inadmite una demanda de amparo interpuesta contra cuatro o sucesivas resoluciones y acuerdos de la Mesa del Congreso de los Diputados relativos al procedimiento seguido para la reforma del artículo $135 \mathrm{CE}$, y no contra la reforma misma ${ }^{3}$. En rigor lo que debía abordar el TC no era la constitucionalidad de dicha reforma, sino la posible lesión de los derechos a ejercer el cargo público sin perturbaciones ilegítimas y en condiciones de igualdad, que el artículo 23.2 CE garantiza a los diputados recurrentes, provocada por las resoluciones de la Mesa del Congreso de los Diputados que arbitraban la tramitación de la proposición de reforma del artículo 135 CE por el procedimiento de tramitación directa, urgente y en lectura única conforme lo prevenido en el artículo 150 del Reglamento del Congreso de los Diputados. En fin, el TC estaba llamado a responder sobre si el procedimiento de reforma de la CE elegido para la ocasión vulneraba el ius in officium de los diputados firmantes de la demanda de recurso de amparo. Y sobre esta precisa cuestión se pronunció el TC en este Auto.

Que así haya sido, que lo elevado al TC sea un recurso de amparo frente a las resoluciones parlamentarias que acordaron la forma de tramitar la reforma constitucional del artículo $135 \mathrm{CE}$, y no un recurso o cuestión de inconstitucionalidad contra la reforma misma, puede explicar por qué el TC no haya hecho cuestión de su propio poder de control sobre las reformas constitucionales. Pero, desde luego, el objeto del debate era la reforma misma. Un oxímoron constitucional que este ATC no ha resuelto del todo, pero que ha apuntado alguna dirección en esta materia sumamente interesante.

2 REQUEJO PAGÉS, J.L, Las normas preconstitucionales y el mito del poder constituyente, CEPC, Madrid, 1998, págs. 102 y ss. Argumentos que vuelve a reiterar en su Comentario al artículo 167 CE, en «Comentarios a la Constitución española. XXX Aniversario», CASAS/RODRÍGUEZ-PIÑERO (Dirs.), Kluwer, Madrid 2008, págs. 2760 y ss.

3 Referencia inexcusable sobre esta reforma es el magnífico número monográfico de esta misma revista, núm. 29, 2012, «La reforma constitucional». 


\section{EL AUTO. UN BUEN PLANTEAMIENTO PARA UN DESENLACE DECEPCIONANTE}

Los recurrentes habían planteado bien su estrategia. Pero el TC soslayó las preguntas importantes que latían (y se hacían) en la demanda de amparo con una resolución de inadmisión que no deja de ser desconcertante. En cierto modo el camino elegido (al margen de consideraciones políticas de otra índole) traslucía la convicción de que técnicamente ni los artículos 161 y 163 CE ni los artículos 27, 35, 59 y 75 bis LOTC permitirían recurrir ante el TC la reforma del artículo 135 CE acudiendo a los procedimientos de declaración de inconstitucionalidad en sus diversas modalidades. No había otra posibilidad, pues, que la de demandar amparo ante el TC por la vulneración que del artículo 23 CE cometía la inadecuación del procedimiento elegido para tramitar la proposición de dicha reforma constitucional. A juicio de los recurrentes, el procedimiento era inadecuado porque, en primer lugar, la proposición de reforma del artículo 135 CE debía tramitarse por la vía del artículo $168 \mathrm{CE}$ pues dicha modificación normativa afectaba el Título Preliminar de la CE, en particular del principio estructural del Estado social del artículo 1.1 CE; y, además, al elegir el procedimiento de reforma del artículo $167 \mathrm{CE}$ se estaban mermando los derechos de participación de ciudadanos y sus representantes parlamentarios al privarles de la convocatoria electoral y el referéndum que sí prevé el artículo $168 \mathrm{CE}$. En segundo lugar, el procedimiento elegido lesionaba gravemente los derechos de los diputados pues, de un lado, les hurtaba trámites de participación (como el debate en comisión de la proposición), de otro, esa lesión también estribaba en la falta de motivación de la decisión de tramitarle por el procedimiento de urgencia y en lectura única, y en la capital reducción del plazo para la presentación de enmiendas que semejante tramitación conllevaba. En suma, el recurso de amparo planteaba que la materia de la reforma del artículo 135 CE no puede considerarse de semejante naturaleza o de formulación tan simple (en los términos del artículo 150 del Reglamento del Congreso de los Diputados) como para justificar su tramitación urgente, directa y en lectura única. Haberlo hecho así, sostiene la demanda, lesionó los derechos del artículo $23.2 \mathrm{CE}$ de los recurrentes.

\section{A. UN RECURSO DE AMPARO QUE DEBIÓ SER ADMITIDO A TRÁMITE}

Lo llamativo, a la par que decepcionante, desde el punto de vista de la técnica procesal, es que semejante cuestión haya sido resuelta mediante un Auto de inadmisión. El voto particular del Magistrado Pablo Pérez Tremps así lo pone de manifiesto. Resulta sorprendente que haya sido así en particular tras la reforma de la LOTC en mayo de 2007. Es difícil creer «que el contenido» del presente recurso de ampro no «justifique una decisión sobre el fondo por parte del Tribunal Constitucional en razón de su especial trascendencia constitucional, que se apreciará atendiendo a su importancia para la interpretación de la Constitución, para su aplicación o para su general eficacia, y para la determinación del contenido y alcance de los derechos fundamentales» (artículo $50.1 \mathrm{~b}$ ) LOTC). Más difícil lo es cuando resulta que los Antecedentes del Auto ponen de manifiesto que no se alcanzó la unanimidad en una de las Secciones de la Sala Segunda para

UNED. Teoría y Realidad Constitucional, núm. 30, 2012, pp. 483-498. 
admitir a trámite la demanda de amparo; y que esta Sala, una vez recibido el recurso (artículo 50.2 LOTC), sugirió al Pleno la avocación prevista en el artículo $10.1 \mathrm{n}$ ) LOTC. El asunto trascendencia constitucional tenía, no cabe duda.

A mayores, la relectura del canon que sentó el propio TC en su STC 155/2009 (FJ 2, preludiada por el ATC 188/2008 ${ }^{4}$ ) relativo a cómo debe interpretarse esa «especial trascendencia constitucional» de la letra b) del artículo 50.1 LOTC, nos deja aún más perplejos. Es difícil escapar a la impresión de que en este recurso no se esté planteando «un problema o una faceta de un derecho fundamental susceptible de amparo sobre el que no haya doctrina del Tribunal Constitucional», o de que el asunto trasciende, en efecto, «del caso concreto porque plante(a) una cuestión jurídica de relevante y general repercusión social o económica» o porque tiene «unas consecuencias políticas generales, consecuencias que podrían concurrir, sobre todo, aunque no exclusivamente, en determinados amparos electorales o parlamentarios».

A pesar de ser ésta la doctrina del TC sobre el mencionado apartado b) del artículo 50.1 LOTC, a pesar de que era la primera vez que se suscitaba ante él la defensa de un derecho fundamental tan transcendental para el Estado democrático de Derecho como es el del ejercicio del cargo representativo en libertad e igualdad del artículo $23.2 \mathrm{CE}$, tan ligado (como el propio TC ha expuesto en infinidad de ocasiones) al de los ciudadanos del apartado 1 de ese mismo precepto de participar en los asuntos públicos, en este caso a través de sus representantes políticos en el Congreso de los Diputados, en punto a la tramitación de una reforma constitucional; y de que, desde luego, la reforma del artículo $135 \mathrm{CE}$, dado el contexto sociopolítico y económico en el que se produjo, no era un asunto baladí; a pesar de todo ello, el TC acordó inadmitir el recurso de amparo.

\section{B. LA RESPUESTA DEL TC A LA CUESTIÓN PLANTEADA}

El TC centra el objeto del debate suscitado en el amparo en dos objetos de impugnación. El primero es el relativo a las resoluciones y acuerdos de la mesa del Congreso de los Diputados, tres en total, que proponen y consuman la tramitación de la proposición de reforma constitucional por el procedimiento de urgencia y en lectura única, fijándose, por lo demás, en la primera de las resoluciones un plazo exiguo de presentación de enmiendas. El segundo se refiere a la impugnación de la resolución y acuerdo que inadmite y confirma la inadmisión de la enmienda a la totalidad con texto alternativo que habían presentado los recurrentes 5 .

4 Sigue siendo de cita inexcusable en este extremo el trabajo de Javier MATÍA PORTILLA, La especial trascendencia constitucional y la inadmisión del recurso de amparo, Revista española de Derecho Constitucional, núm.86, 2009, págs. 343 y ss.; y los de Mario HERNÁNDEZ RAMOS, El nuevo trámite de admisión del recurso de amparo constitucional, Reus, Madrid, 2009; y Propuesta de desarrollo del nuevo trámite del recurso de amparo: aspectos materiales y procedimentales, Revista de las Cortes Generales, núm. 73, 2008, págs. 31 y ss.

5 Un examen detallado del procedimiento parlamentario lo ha hecho GARCÍA-ESCUDERO MÁRQUEZ, P en su trabajo La acelerada tramitación parlamentaria de la reforma del artículo 135 de la Constitución (Especial consideración de la inadmisión de enmiendas. Los limites al derecho de enmienda en la reforma constitucional), Teoría y Realidad Constitucional, núm. 29 (monográfico «Lo reforma constitucional»), 2012, págs. 165 y ss.

UNED. Teoría y Realidad Constitucional, núm. 30, 2012, pp. 483-498. 
Ya hemos expuesto más arriba los motivos impugnatorios (todos ellos en realidad sustanciales, pues expresan la disconformidad con la tramitación de la reforma por la vía menos agravada del artículo $167 \mathrm{CE}$ y el que pueda considerarse la reforma del artículo $135 \mathrm{CE}$, dada su trascendencia política y económica, apta para ser tramitada de forma urgente y en lectura única por su naturaleza o formulación simple). La pretensión deducida por los recurrentes era la declaración de nulidad de todos las resoluciones y acuerdos atacados en el amparo, con la consiguiente restitución del tramite de reforma al momento de la publicación de la proposición, que debiera tramitarse por el procedimiento del artículo $168 \mathrm{CE}$, o, subsidiariamente, de tramitarse por la vía del artículo $167 \mathrm{CE}$, que no se hiciese por el trámite de urgencia y en lectura única.

El TC se limitó en el ATC 9/2012 a inadmitir la demanda de amparo. Vamos a dejar para el siguiente subsección de este apartado lo relativo al rechazo de la queja respecto de la decisión de tramitar la proposición de reforma constitucional por el trámite del artículo $167 \mathrm{CE}$.

Ahora se abordará el rechazo por el TC de las esgrimidas vulneraciones del ius in officium de los diputados recurrentes. Para el TC no ha habido lesión alguna del artículo 23.2 CE. Las decisiones de la Mesa del Congreso de los Diputados relativas a la tramitación de la proposición de reforma del artículo 135 CE no han privado, ni limitado ni restringido las facultades de los parlamentarios para participar en el debate plenario sobre la reforma propuesta ni las normas reglamentarias que regulan el proceder del Congreso de los Diputados excluyen del trámite de urgencia y en lectura única de las reformas constitucionales, ni les fue impedida la posibilidad de presentar enmiendas (como así lo probaba, dice el TC, la circunstancia de que pudieran presentar una enmienda a la totalidad con texto alternativo) — FFJJ 3 y 4-. Asimismo, el TC rechaza también las impugnaciones de la resolución y acuerdo que inadmitió y confirmó la inadmisión respectivamente de la enmienda a la totalidad con texto alternativo que presentaron los recurrentes, pues, siguiendo su doctrina reiterada, no sólo la inadmisión estaba formalmente motivada, además lo hacía señalando, como también lo ha hecho el TC en otras ocasiones, que debe existir una coherencia material entre la enmienda presentada y el objeto enmendado de forma que resulta constitucionalmente correcta la inadmisión de una enmienda a la totalidad que en realidad suponía una nueva proposición de reforma constitucional no sólo del artículo $135 \mathrm{CE}$, y que exigía por lo demás tramitarla por el procedimiento del artículo $168 \mathrm{CE}$ (FJ 5). El Pleno no tiene reparo en utilizar un argumento harto formalista para terminar de despachar el asunto según el cual, en último término ha sido la decisión de la mayoría parlamentaria expresada en la pertinente votación plenaria del Congreso de Diputados la que ha acordado dar el trámite que ha recibido la proposición de reforma constitucional del artículo 135, en cuyo debate y votación tuvo participación el grupo de diputados recurrentes.

El TC en su Auto parece incurrir en un cierto formalismo parlamentario enervante, por el cual queda sanada cualquier decisión razonablemente dudosa desde la perspectiva del procedimiento democrático por la actuación plenaria del órgano legislativo correspondiente. Olvida el TC que también es doctrina suya la que sostiene que el debate parlamentario tiene una función que trasciende la meramente formal para la creación de una opinión pública avisada de los asuntos sobre los que deciden las Cortes Generales y que, en rigor y según qué casos, no debiera bastar el formalismo de acudir al respeto de los re- 
glamentos parlamentarios para considerar satisfecha la exigencia constitucional de un debate público y plural, pero sobre todo útil, que impone el principio democrático.

\section{Una lección de Derecho Constitucional. La Respuesta del TC a la CONTROVERTIDA INTERPRETACIÓN EXTENSIVA DEL ARTÍCULO 168 CE}

Con todo, el interés de este Auto trasciende la cuestión, de suyo capital, relativa a las competencias del TC para el control de constitucionalidad de una reforma constitucional. El TC, como ya había hecho en su Declaración 1/1992, de 1 de julio, se pronuncia expresamente sobre la controvertida, permítasenos denominarla, interpretación extensiva del artículo 168 CE. Como es bien sabido, se trata de un lugar común en el debate doctrinal sobre la reforma constitucional regulada en el Título X CE el relativo a si ha de interpretarse en sentido literal y riguroso el ámbito material limitado a ese procedimiento agravadísimo de reforma, o también debe considerarse sujeto a él la modificación de cualesquiera otros preceptos constitucionales cuya revisión tenga el efecto de alterar sustancialmente el sentido y significado de cualquiera de los que sí están encuadrados en el Título Preliminar, en el Capítulo 2, Sección $1^{\text {a }}$ del Título I o en el Título II de la CE.

«En efecto, el texto constitucional establece de manera precisa la finalidad de las dos vías de reforma que prevé, en función de los objetos sobre los que se puede proyectar, de tal modo que admitir la pretensión de los recurrentes alteraría el equilibrio buscado por el constituyente, corriendo el riesgo de dejar a la discreción del órgano rector de la Cámara la determinación del procedimiento de reforma constitucional. La posible afección de la modificación de un precepto de la Constitución a otros de la misma norma ha sido considerada por este Tribunal con ocasión de la Declaración 1/1992, de 1 de julio, dictada previa consulta del Gobierno de la Nación, al amparo del art. 95.2 CE, en relación con la reforma del art. 13.2 CE, concluyendo que «al no contrariar el precepto examinado otra norma de la Constitución distinta al art. 13.2 de la misma, el procedimiento para la revisión constitucional que prevé el art. 95.1, ha de ser el de carácter general u ordinario contemplado en el art. 167 de nuestra Ley fundamental» (FJ 6)» (FJ 2)

No es éste un asunto baladí, ni debe considerarse un excursus innecesario detenernos ahora en él. Lo que en definitiva plantea que nuestro sistema constitucional identifique unos preceptos cuya reforma está sujeta a un procedimiento agravado, que intensifica la rigidez de la $\mathrm{CE}$, es la existencia en ella de un «núcleo constitucional» que, por emplear la expresión del BVerfGE 2 BeV 2/08 de 30 de junio de 2009 sobre el Tratado de Lisboa, materialice la «identidad constitucional» del Estado español para cuya modificación o alteración debe seguirse el procedimiento del artículo $168 \mathrm{CE}$, aunque formalmente el objeto literal de la reforma sean preceptos no encuadrados en los reservados al trámite regulado en él.

No han sido pocos los autores que han sostenido que la materia reservada al procedimiento del artículo 168 CE no es el que cabe deducir sin más y simplemente de su tenor literal, sino que se extiende a todos aquellos otros preceptos constitucionales que, aun estando fuera de los Títulos y Secciones literalmente mencionados en ese precepto, constituyen «la corporeización que de ellos (de la definición y el alcance de los principios 
estructurales de la $\mathrm{CE}$ ) han efectuado» esos preceptos sujetos ahora a revisión ${ }^{6}$. La razón dogmática de que así sea estriba en último término en que se tutelaría más severamente la revisión de unos preceptos cuyo contenido y desarrollo constitucional debe hallarse en otros de más fácil modificación, de manera que lo sujeto a un procedimiento agravadísimo de reforma sería más el contenido de unos preceptos deducible de su interpretación dogmática apriorística e ideológica, y no el que resulta de la interpretación sistemática y constitucionalmente conforme que de ellos debe hacerse a la luz de los que a lo largo del texto constitucional los precisan y desarrollan. Alterar éstos, supone alterar el sentido y alcance de aquéllos, por lo que reformar los primeros por el procedimiento ordinario del artículo 167 CE, cuando su modificación alteraría el contenido de los segundos en la medida en que se cambia el sentido que aquéllos le daban en su redacción original, incurriría en un supuesto de fraude constitucional .

Que así sea les ha permitido concluir en lo que ahora interesa, que la Mesa del Congreso de los Diputados estaría obligada a calificar la proposición de reforma para determinar qué procedimiento debe seguirse en su tramitación «y que resultará controlable jurisdiccionalmente» ${ }^{8}$. Justamente, la resolución que así lo hizo en el caso de autos ha sido objeto del recurso de amparo del que trae causa el ATC 9/2012.

A nuestro juicio, en la tesis del TC late indudablemente su prevención dogmática inveterada a las petrificaciones del ordenamiento jurídico fruto de la imposición de mayorías cualificadas o agravadas. Esa rigidez siempre ha sido vista por el TC como un límite al principio democrático que debe aplicarse con cautela y sujeto a una interpretación restrictiva. Así, como es sabido, lo ha sostenido el TC para el caso de la interpretación del alcance de la reserva de ley orgánica desde la STC 5/1981. En este caso el TC aplica la misma tesis y mantiene que no cabe una interpretación extensiva de la materia reservada a la reforma agravada del artículo $168 \mathrm{CE}$ porque, en último término, y como la propia resolución del TC expresa, se otorgaría a la Mesa de la Cámara un poder de disposición sobre la reforma misma al decidir sobre su cauce procesal más allá de lo que resulta de la propia literalidad de los preceptos a reformar, y en consecuencia un poder sobre el alcance de la propia rigidez constitucional al quedar a su albur determinar si la reforma pretendida debe llevarse por uno u otro cauce, y por consiguiente, la mayor o menor dificultad en que la reforma prospere. Pero lo hace, así lo creemos, de manera defectuosa haciendo uso de una cita errónea. Aquí, al contrario que lo sucedido con la modificación del artículo 13.2 CE a resultas de la ratificación del Tratado de Maastrich, no se trataba de dilucidar una contradicción literal entre una norma y la CE. En este caso tendría sen-

6 PUNSET BLANCO, R en su trabajo El control jurisdiccional de la actividad de las Asambleas Parlamentarias y del Estatuto de sus miembros en el derecho español, que se cita por su edición en Estudios Parlamentarios, CEPC, Madrid, 2001, págs. 369 y ss, págs. 376 y ss. PUNSET en esto sigue la estela y desarrolla la tesis que ya había expuesto OTTO Y PARDO, I de en su trabajo Sobre la naturaleza del Estado de las Autonomías y la relación entre Constitución y Estatutos, que se cita por «Ignacio de Otto y Pardo. Obras completas», CEPC/Universidad de Oviedo, Madrid, Oviedo, 2010, págs. 706 y ss, págs. 707 y s; y que reitera en su Derecho Constitucional. Sistema de Fuentes, que se cita también por sus «Obras Completas», pág. 856. Véase también de ALÁEZ CORRAL, B Los límites materiales a la reforma de la Constitución Española de 1978, CEPC, Madrid, 2000, págs. 323 y ss.

7 Véase DE VEGA, P La reforma constitucional y la problemática del poder constituyente, Tecnos, Madrid, págs. 291 y ss.

8 PUNSET BLANCO, R, ob.cit., pág. 377.

UNED. Teoría y Realidad Constitucional, núm. 30, 2012, pp. 483-498. 
tido atenerse a la literalidad de los preceptos dado el alcance limitado de la propia reforma y su origen (evitar la incorporación al ordenamiento jurídico español de normas contrarias a la CE ictu oculi).

El caso es bien distinto, pues no se trata de resolver una contradicción normativa literal entre la CE y otro precepto que se quiere incorporar al ordenamiento jurídico español, sino de comprobar si una reforma de la propia norma constitucional, esto es, la modificación inmediata de la literalidad de un precepto constitucional, es contraria a la propia CE. En ese caso, la cita de la Declaración 1/1992, de 1 de julio no ayuda nada a sostener el argumento, por cuanto, más allá de la literalidad del precepto propuesto, debe analizarse si su introducción en la CE provoca alteraciones en, justamente, aquellos preceptos que si están encuadrados en la materia reservada al trámite del artículo 168 CE'.

Ahora bien, de nuestras palabras no debe inferirse que esta interpretación extensiva del artículo 168 CE permita dar pábulo a la existencia implícita de un «núcleo» de la CE en el que se atesora la identidad constitucional del Estado y que sirve de parámetro de control de las pretendidas reformas constitucionales. En absoluto, la interpretación extensiva de ese precepto, que el TC rechaza en su ATC 9/2012, se asienta en una interpretación sistemática de la CE según la cual, como arriba se ha dicho ya, la alteración que sufran preceptos cuya reforma no está sujeta al artículo $168 \mathrm{CE}$, puede conllevar un cambio sustancial del contenido y alcance de los que sí lo están. Cosa distinta es que la propia interpretación extensiva del precepto, dada su trascendencia al imponer un trámite más dificultoso y unas mayorías parlamentarias más agravadas para modificar la CE, exija, sin embargo, la autorrestricción de la Mesa del Congreso de los Diputados en su empleo y una mayor motivación de su calificación cuando considere que en efecto debe extenderse el trámite del artículo 168 a modificaciones de preceptos que no son su objeto ${ }^{10}$.

\section{LOS VOTOS PARTICULARES}

Son tres los votos formulados: los concurrentes de los Magistrados Eugenio Gay Montalvo y Luis Ignacio Ortega Álvarez, y el discrepante del Magistrado Pablo Pérez y Tremps.

En el primero, la discrepancia tiene que ver con ese formalismo parlamentario enervante al que nos hemos referido líneas atrás. Para el Magistrado la relevancia política del asunto objeto de la reforma constitucional del artículo 135 CE y su trascendencia impide, en su opinión, que pueda considerarse la propuesta «simple en su formulación», y consiguientemente, injustificado el recurso al trámite de urgencia y en lectura única. Para el Magistrado el mismo amplio consenso político que alumbró la CE debe buscar-

9 El voto particular del Magistrado Luis Ignacio Ortega Álvarez repara en estas cuestiones e insiste en la necesidad de distinguir entre la función de las Cortes Generales y el producto normativo que resulta del ejercicio en un caso del poder constituido de legislar del constituyente de reformar la Constitución. Sobre esto se volverá más abajo.

10 Hacemos nuestra en este particular la tesis que, además de los citados, desarrolla Benito ALÁEZ CORRAL, ob.cit., págs. 303 y ss. 
se en sus reformas, lo que exige que éstas se sujeten a procedimientos legislativos que hagan efectiva la participación y debate de la propuesta de todas las fuerzas políticas representadas en el hemiciclo.

El Magistrado Luis Ignacio Ortega Álvarez en su voto concurrente incide justamente en el papel del TC en el control de constitucionalidad de las reformas constitucionales y lo hace, expresando el sumo respeto al ámbito competencial de las Cortes Generales en ese trámite, señalando dos cuestiones. La primera relativa a la efectiva posibilidad de que se acuda al procedimiento del artículo 167 CE escudados en la literalidad y ubicación de la norma sujeta a modificación para esconder la alteración de las materias que están, por el contrario, sujetas al procedimiento agravado del artículo 168 CE. La segunda cuestión se refiere a la necesidad de distinguir la función que desempeñan las Cámaras parlamentarias cuando reforman la CE y el distinto valor jurídico del producto normativo que nace de ese procedimiento. A juicio del Magistrado discrepante, el TC tiene el poder de controlar el respeto a esas condiciones constitucionales de la reforma, sin por ello dejar de ser escrupulosamente respetuoso con el ámbito propio del legislador que es a quién la CE atribuye en exclusiva la función de reformar la CE.

Finalmente. el voto del Magistrado Pablo Pérez Tremps muestra su radical discrepancia con la forma de solventar la demanda de amparo mediante un Auto de inadmisión. El Magistrado considera que no cabe duda alguna sobre la trascendencia constitucional del asunto sometido al conocimiento del TC: una reforma constitucional tramitada irregularmente según los diputados recurrentes, legítimos representantes políticos de los ciudadanos. A ello añade su reproche al TC que haya efectuado en sede de admisión un juicio de fondo sobre la existencia o no de la lesión denunciada en el recurso de amparo, cuando no resultaba evidente ictu oculi la inexistencia de la vulneración del artículo 23.2 CE denunciada. Ese juicio debió hacerse en Sentencia y no anticipado, indebidamente, en el trámite de admisión de la demanda de amparo.

\section{CONCEPTOS Y PALABRAS. EL OXÍMORON DEL CONTROL DE CONSTITUCIONALIDAD DE LA REFORMA CONSTITUCIONAL}

Existe un cierto acuerdo pacífico sobre el hecho de que el TC sólo puede controlar el proceder para reformar la CE, pero no su contenido. Dos son las razones que avalan esta tesis, y que aquí se comparten. La primera es el hecho de que, por definición, toda reforma constitucional es contraria a la Constitución que pretende reformar. No hay que extenderse en explicar que una norma que pretende alterar o modificar otra norma la contradice. Cosa distinta, es aquella reforma que trata de incorporar nuevas normas a la CE o complementar una existente. Tampoco hay que demorarse en muchas explicaciones para comprender que en estos casos, la ausencia de contradicciones, al menos en un principio, entre la CE o la norma constitucional que se ve complementada por la resultante de su reforma, hace superfluo el control, a salvo que contradiga otras normas constitucionales. En ese caso, también deben considerarse reformadas éstas; a lo que resulta de aplicación la primera de las hipótesis expuesta. La segunda razón estriba en la ausencia de cláusulas de intangibilidad en la CE. La CE no posee contenidos normativos inmodificables; todo en ella puede ser revisado, alterado, reformado. Desde esta perspectiva, el control del TC 
sobre el contenido, en rigor, no es que resulte imposible, resulta superfluo; lo que no es lo mismo. Si la CE puede cambiar en su totalidad, no hay reformas inconstitucionales, sino una simple sucesión de normas constitucionales en el tiempo cuya validez deriva de su adecuación a los procedimientos de reforma que prevé la CE. La preguntas que deben hacerse en puridad se refieren, de un lado, a si las reformas son inválidas si incumplen con las normas de reforma constitucional; de otro, si el TC puede conocer y pronunciarse sobre esta circunstancia.

El ATC 9/2012 responde positivamente a esta última cuestión; aunque inadmita el recurso de amparo. Es así porque la inadmisión se alcanza al considerar el TC que no existe lesión de derecho fundamental alguno en las resoluciones y acuerdos de la Mesa del Congreso de los Diputados objeto de impugnación; no porque se considere incompetente o inadecuado el procedimiento elegido para realizar ese juicio de constitucionalidad. Su silencio sobre este particular apunta precisamente a que sí se considera competente para conocer de una reforma constitucional pronunciándose sobre si los actos parlamentarios que la elaboran vulneran o no derechos fundamentales.

En efecto, una cosa es examinar si el TC puede conocer impugnaciones de reformas constitucionales, y otra si conocerlas o no resultaría superfluo. Los argumentos anteriores apuntan a esto segundo, pero dejan sin resolver la cuestión sobre si el TC es constitucionalmente competente para conocer de impugnaciones de reformas constitucionales. A nuestro juicio, no existe en la CE ni en la LOTC ningún precepto que permita al TC conocer de semejantes impugnaciones a través de ninguno de los procedimientos de control de constitucionalidad que regula su ley Orgánica; a salvo que consideremos a las reformas constitucionales «leyes» de reforma constitucional ${ }^{11}$. Sin embargo, sí es posible sujetar a control los actos de los poderes públicos que componen el proceso de elaboración de la reforma constitucional. Justo esto es lo sucedido en el caso de autos. Lo que se somete a conocimiento del TC son actos de elaboración de la reforma, no la reforma en sí misma considerada ${ }^{12}$. Por la naturaleza de esos actos, y por paradójico que pueda resultar, el único medio para realizar esa impugnación es el recurso de amparo; única vía procesal para llevar una reforma constitucional ante el TC. Y, además, tan sólo por lesión del ius in officium de los parlamentarios, dado que esos actos impugnables lo son del artículo 42 LOTC; esto es, interna corporis acta de las Cámaras. Lo que se puede elevar al TC por medio de un recurso de amparo es el conjunto de actos parlamentarios de elaboración de la reforma constitucional, y no la reforma misma, por cuanto ésta no es ninguno de los objetos impugnables a través de ese recurso (artículos 42, 43 y 44 LOTC).

Pero esta vía plantea una cuestión no menor que no llega a resolver el TC en el ATC 12/2012: ¿qué consecuencia tendría sobre la reforma constitucional la nulidad de los actos de su elaboración por vulneración de derechos fundamentales? Vayamos por partes.

11 Como hace, por ejemplo, PÉREZ ROYO, J en su Las fuentes del Derecho, Tecnos, Madrid, 1993 ( $4^{\mathrm{a}}$ edic.), págs. 41 y ss.

12 Por todos véase ALÁEZ CORRAL, B, Los límites materiales a la reforma de la Constitución Española de 1978, CEPC, Madrid, 2000, págs. 385 y ss. 


\section{A. LA IMPOSIBILIDAD LÓGICA Y JURÍDICA DEL CONTROL MATERIAL DE CONSTITUCIONALIDAD DE LAS REFORMAS CONSTITUCIONALES EN EL ORDENAMIENTO ESPAÑOL}

Este es un debate que, como señala ALÁEZ, pende directamente de la concepción que se tenga de la naturaleza de las normas constitucionales. Aquellos sistemas en los que predomina un concepto material de Constitución, como el alemán e incluso el italiano, está en la naturaleza misma del sistema constitucional que la jurisdicción constitucional pueda controlar y pronunciarse sobre la compatibilidad de la reforma constitucional con la Constitución «material» de ese sistema, identificada con el «núcleo constitucional» que salvaguarda la «identidad constitucional» del Estado, expresión directa de la voluntad soberana del Pueblo. De este modo, la posibilidad jurídica de ese control es una exigencia misma de la Democracia ${ }^{13}$. Así lo ha expresado el BVerfG alemán ${ }^{14}$, la Corte Costituzionale italiana ${ }^{15}$ o el Verfassungsgerichtshof austríaco ${ }^{16}$.

Desde luego, el punto de partida no puede ser el que adoptó en su momento Otto BACHOF para justificar el control por el Poder Judicial, no sólo por el BVerfG, de las normas de reforma constitucional si éstas fuesen sospechosas de inconstitucionalidad. Según la tesis bien conocida del ilustre maestro alemán, la «competencia judicial de control», para este caso de las leyes de reforma constitucional, es un «instituto jurídico del ordenamiento» prexistente a cualquier Constitución. No se trata de un poder otorgado por el poder constituyente, sino de una suerte de derecho natural de los jueces y tribunales, inherente a su propia existencia y función, fundado «únicamente en la idea de «justicia». Al margen de otras consideraciones, baste con recordar aquí que no hay poder público, tampoco el jurisdiccional, cuya fuente no esté justamente en la voluntad del constituyente expresada en la Constitución; única fuente por demás de la legitimidad democrática del ejercicio de ese poder por jueces y magistrados. El profundo entreveramiento de Estado de derecho y principio democrático no dejan lugar a dudas sobre este extremo.

13 Este debate está magníficamente resumido en el libro ya citado de Benito ÁLAEZ CORRAL. Véase los trabajos de MURSWIECK, D, Die verfassungsgebbende Gewalt nach dem Grundgesetz für die Bundesrepublik Deutschland, Duncker \& Humblot, Berlin, 1985, págs. 387 y ss; HIESEL, M Verfassungsgesetzgeber und Verfassungsgerichtshof, Manz'sche, Wien, 1995; y NOLL, A.J, Verfassunggebung und Verfassungsgerich, Springer, Wien/New York, 1995.

14 BVerfGE1, 14, 17, 18, 61 (de todas ellas da cuenta el libro de ÁLAEZ, ob.cit., pág. 391). El BVerfG en su decisión de 30 de junio de 2009 sobre el Tratado de Lisboa recuerda una doctrina reiterada y arraigada en el sistema jurídico alemán y su dogmática según la cual le compete a aquél velar en las reformas constitucionales sobre la intangibilidad de la «identidad constitucional» que el artículo 79.3 de la Ley Fundamental de Bonn establece para la República Federal de Alemania. El sustento dogmático constitucional de semejante control jurisdiccional sobre el ejercicio del poder constituido-constituyente no es otro, añadimos nosotros, acaso no pueda ser otro, que controlar que el poder constituyente del pueblo no haya sido «usurpado», dice el BVerfG, por los poderes constituidos, a los que el constituyente «no ha dado mandato alguno para poder disponer sobre (esa) identidad constitucional» ( $\$ 218$ y 219). Curiosamente, esta tesis se corresponde más con la que aquí se defiende que en la dominante en el sistema jurídico alemán de la que se ha dado cuenta más arriba.

15 Véase de la Corte Costituzionale la Sentenza núm. 1146/1988 (de la que también da noticia ÁLAEZ, ob.cit., pág. 391). Véanse los distintos trabajos del libro VARIOS AUTORES, Cambiare costituzione o modificare la Costituzione?, RIPEPE/ROMBOLI a cura, Giappichelli, Torino, 1995.

16 De cuyas resoluciones dan cuenta los libros de NOLL y HIESEL ya citados. 
Para esta dogmática «material» de la Constitución, las reformas constitucionales no son más que «leyes» que están habilitadas por la propia Constitución para modificarla. Los procedimientos de reforma constitucional constituyen habilitaciones que atribuyen al poder legislativo, en su condición de órgano de representación política de los ciudadanos, la competencia de modificar la Constitución. El producto normativo seguiría siendo una «ley», pero sin el poder de alterar su núcleo, materializado en sus cláusulas de intangibilidad. Para esta concepción, la reforma constitucional constitucionalmente conforme no es más que una excepción a la supremacía constitucional permitiendo que la ley pueda modificar la Constitución a pesar de su inferioridad jerárquica, siempre que se sigan determinados procedimientos que la hagan formalmente identificable como ley de reforma constitucional, y respetando ciertos límites materiales (las cláusulas de intangibilidad). El papel de la jurisdicción constitucional es comprobar que así es. Y en su papel está, pues lo que efectúa no es más que el control de constitucionalidad de una «ley», que, si ha respetado el procedimiento de elaboración previsto para el caso y las cláusulas de intangibilidad constitucional, esa ley está constitucionalmente habilitada para modificar la propia Constitución sin incurrir en inconstitucionalidad ${ }^{17}$.

A nuestro juicio, por el contrario, en el sistema jurídico español ni existe una Constitución «material» corporeizada en núcleo constitucional alguno, ni las reformas constitucionales (y no debe ser casual que la proposición de reforma del artículo $135 \mathrm{CE}$ se hubiese denominado así y no «ley» de reforma constitucional) son «leyes» o normas con rango o fuerza de ley. Así es en tanto la CE no posee cláusulas de intangibilidad, ni siquiera el artículo $168 \mathrm{CE}$ identifica un núcleo constitucional intangible o que sirva de parámetro de control de las reformas constitucionales; ni las reformas constitucionales son productos legislativos por mucho que el órgano que llama la CE para realizarlas sean las Cortes Generales. Tampoco es baladí que el TC haya guardado un escrupuloso silencio sobre estos extremos en su ATC 9/2012 (silencio que, así lo creemos, sutilmente le reprochan sus votos particulares, especialmente el del Magistrado Luis Ortega Álvarez).

\section{B. ¿QuiÉn Reforma? Poder constituyente-COnstituido vs. Poder CONSTITUIDO-CONSTITUYENTE}

Esta pregunta que puede parecer una boutade trata de expresar las dos formas de comprender la cuestión. La dogmática resumida en el epígrafe anterior no deja de ver en el poder legislativo un poder constituido que bajo ciertas condiciones se eleva a constituyente reformando la Constitución con sus leyes. Sin embargo, la que aquí se trata de defender es que el Título $\mathrm{X}$ de la $\mathrm{CE}$ no regula una competencia del poder legislativo para reformar la CE, sino un poder de reforma constitucional que se sirve del legislativo para elevarlo a la condición de poder constituyente-constituido capaz de producir normas constitucionales cuya validez deriva de su adecuación a los procedimientos de reforma regulados en el Título X de la CE. Adecuación que únicamente debe ser formal, puesto que la CE carece de cláusulas de intangibilidad y prevé su reforma total, lo que impide en pu- 
ridad técnica la existencia de un parámetro material, directo o reflejo, de la constitucionalidad de las reformas constitucionales.

El voto particular que formuló el Magistrado Luis Ortega Álvarez al ATC 9/2012 expresó justo la necesidad de distinguir entre «... los procedimientos parlamentarios legislativos, en los que las Cortes como institución y los representantes del pueblo actúan como órganos y poderes constituidos y los procedimientos parlamentarios de reforma constitucional, en los que actúan como poder constituyente. Como defensor de la Constitución, este Tribunal podría haber exigido que se respetase el valor supraordenado de la norma Constitucional respecto de los productos normativos emanados de las Cámaras legislativas». Así lo entendemos nosotros también.

En nuestra opinión, cuando la CE llama a las Cortes Generales a reformar no está llamando al órgano que hace leyes ejerciendo la soberanía representando al conjunto de los ciudadanos, sino al órgano que representa al soberano popular, al órgano que da cuerpo a la Nación española para ejercer su soberanía empleando el poder de reforma, esto es, la competencia para de producir normas constitucionales (por eso no es baladí el trámite del referéndum, como vehículo de expresión de la opinión de las «generaciones vivas», de los ciudadanos, que de este modo se incorporan al proceso constituyente). El órgano y sus procedimientos pueden ser idénticos y similares, pero no su función ni su producto ${ }^{18}$.

Del mismo modo El TC está constitucionalmente diseñado, como lo está en rigor la jurisdicción constitucional, para controlar el producto normativo de las Cortes Generales en su condición de órgano de representación política de los ciudadanos, cuya voluntad normativa sólo es imputable a la del soberano en cuanto no son declarados inconstitucionales. En puridad la misión constitucional del TC es declarar esa inconstitucionalidad de existir. Pero para que así pueda ser, debe haber un parámetro de control que dé sentido jurídico a ese juicio de constitucionalidad. La ausencia de parámetro, imposibilita lógica y jurídicamente el control y la posible declaración de inconstitucionalidad. Y ese parámetro sólo se da si entre la norma controlada y la que sirve de criterio para su control existe una relación jerárquica.

Pues bien, así lo creemos, en una reforma constitucional no existe parámetro de control material de su constitucionalidad porque el producto normativo que reforma la Constitución posee el mismo rango que la Constitución que modifica. Incluso existiendo «núcleos constitucionales», la única consecuencia de semejante control es que la reforma constitucional que los contradiga dejará de hallar su fuente de validez en las normas constitucionales de reforma, y lo que fue una reforma en sus inicios se transforma en una «ruptura constitucional» ${ }^{19}$.

18 Este mismo planteamiento se puede seguir en el debate que en su momento mantuvieron Lawrence TRIBE, H. y DELLINGER, W.E, a través de sus artículos, A Constitution we are amending: in Defense of a Restrained judicial Role, y The legitimacy of Constitutional Change: rethinking the Anmending Process; ambos en la Harvard Law Review, Vol.97, núm.2, 1983, págs. 433 y ss, y págs. 387 y ss, respectivamente. Interesantes también los trabajos de HENKIN, L Is there a Political Question Doctrine?, Yale Law Journal, Vol. 85, núm. 5, 1976, págs. 597 y ss; y el clásico de ORFIELD, L.B, The Amending of the Federal Constitution, Chicago, Michigan Legal Studies, Chicago, 1942, Capítulo II.

19 En este sentido los trabajos ya citados de REQUEJO PAGÉS, J.L. Consúltese también el de CARPIZO, J, El Tribunal Constitucional y el control de la reforma constitucional, Boletín Mexicano de Derecho Comparado, núm. 125, 2009, págs. 735 y ss. 
Así concebida la forma y contenido de las normas que reforman la CE, su naturaleza excede del ámbito sujeto al control de la jurisdicción constitucional. La función del TC es impedir la usurpación del poder constituyente por los poderes constituidos. Por esa razón los procedimientos a través de los que el TC ejerce esa función tienen por objeto los productos normativos de los poderes constituidos, pero no pueden serlo los de los poderes constituyentes. En ese caso, y como bien expuso Juan Luis REQUEJO ${ }^{20}$, ni lógica ni jurídicamente la reforma es un producto legislativo, sino constitucional; y no es competencia del TC controlar el ejercicio del poder constituyente por mucho que ese poder sea atribuido por la Constitución a un poder constituido. Es la propia rigidez constitucional la que define esa mutación de sustancia en virtud de la cual las Cortes Generales se transforman en poder constituyente(-constituido) cuyo producto normativo ya no es una norma con rango y/o fuerza de ley, sino una norma constitucional.

Sin embargo, la imposibilidad lógica y jurídica de que se sometan al conocimiento del TC las normas de reforma constitucional por su contenido, no impide que, como se ha apuntado más arriba, resulte posible que de esa reforma conozca el TC porque se pueda formular, como ha sido el caso en el ATC 9/2012, un recurso de amparo en el que se denuncie la lesión de derechos fundamentales provocada por los actos de elaboración de la reforma.

Así es, pues en ese caso, lo que es objeto de control por el TC son actos, que no normas; y actos constitucionalmente reglados. Lo que el TC examinó en el ATC 9/2012 no fue una reforma constitucional, sino los actos de la Mesa del Congreso de los Diputados que la elaboraron. No habría otra, por lo demás, pues dichos actos sólo podrían ser atacables a través del recurso de amparo (artículo 42 LOTC). El problema en este caso no es tanto la lógica y mecánica del enjuiciamiento de dichos actos, cuanto los efectos que la resolución del recurso de amparo pueda tener sobre la reforma producto de unos actos de elaboración que pueden llegar a ser declarados nulos por vulneración de derechos fundamentales.

\section{ALGUNAS CUESTIONES PENDIENTES}

Es verdad que con esto estaremos haciendo ciencia ficción (si es que llegados a esta altura de los tiempos el Derecho Constitucional no se ha convertido ya en un ejercicio de tal calibre), pero sería bueno preguntarse si, en el caso de que efectivamente se hubieran declaradas nulas las resoluciones de la Mesa del Congreso de los Diputados objeto del recurso, la reforma constitucional se vería contagiada de esa misma nulidad. La opinión que probablemente sostendría el TC se podría encontrar en la STC 119/2011, que el propio TC cita en su Auto. En esa STC 119/2011, a pesar de estimar el amparo por la lesión del artículo 23.2 CE de los diputados recurrentes contra las resoluciones de la Mesa del Congreso de Diputados que admitieron a trámite dos enmiendas a la Ley Orgánica 20/2003, de 23 de diciembre, de modificación de la Ley Orgánica del Poder Judicial y del Código

20 Expresado en sus trabajos REQUEJO PAGÉS, J.L, Las normas preconstitucionales..., ob.cit., págs. 102 y ss; y Comentario al artículo 167 CE, ob.cit., págs. 2760 y ss.

UNED. Teoría y Realidad Constitucional, núm. 30, 2012, pp. 483-498. 
penal, consideró que no era necesario pronunciarse sobre las consecuencias que dicha nulidad tenía sobre la citada Ley Orgánica. Así lo despacha en este lacónico FJ 10:

«En cuanto al alcance del otorgamiento del presente amparo, y en los términos expuestos por el Ministerio Fiscal, bastará con el reconocimiento del derecho vulnerado y con la anulación de los acuerdos impugnados. Tampoco procede realizar en este recurso de amparo ningún pronunciamiento ni deducir efecto alguno de su fallo sobre la constitucionalidad de los preceptos afectados de la Ley Orgánica 20/2003, de 23 de diciembre»

Acaso pesó en la decisión del TC que al tiempo de esta Sentencia la Ley Orgánica 2/2005, de 22 de junio, de modificación del Código Penal había dejado sin efecto la reforma del año 2003 de la que traía causa el amparo en cuestión.

Desde luego precisar los efectos de una hipotética STC que declarase contrario a la $\mathrm{CE}$, formal o materialmente, una reforma constitucional posee enorme trascendencia; y es un asunto casi aun más relevante que el análisis de quién, qué y cómo se controla la constitucionalidad de la reforma constitucional.

Quede aquí como cuestión pendiente, pues su análisis excede con mucho el objeto de este comentario al ATC 12/2012. Pero no nos resistimos a aventurar que ese posible fallo estimatorio de una lesión del artículo 23.2 CE en la tramitación de la reforma constitucional quedase en una mera declaración de nulidad derivada y refleja de la reforma, la cual, no obstante permanecería en el ordenamiento jurídico. En efecto, la Sentencia que declarase nulos los actos de elaboración de la reforma constitucional, sólo privarían de forma derivada y refleja de su fuente de validez a la reforma constitucional así aprobada. Pero la circunstancia de que se rompa esa cadena de validez entre la Constitución reformada y las normas que la reforman, tan sólo conlleva una mutación en esa revisión constitucional, que se habría transformado en una ruptura constitucional dando lugar al nacimiento de una nueva Constitución cuya validez ya no provendría de aquélla a la que sustituye. Parafraseando a Javier Pardo Falcón, aún seguimos a la espera de que nuestro Juez constitucional diga algo sobre este particular. Repárese en que, si un recurso de amparo ordinario no puede esconder un control de constitucionalidad de la ley, se nos antoja imposible que surta ese efecto en el caso de autos.

$$
\text { *** }
$$

TITLE: The constitutional control of constitutional reforms: A constitutional oxymoron? Comment on ATC 12/2012

ABSTRACT: In this article the author analyses ATC 9/2012 that refuse to process the application for liberties warrant lodged by several parliamentarians against the resolutions and agreements of the Bureau of the Chamber of Deputies which gave the reform of article 135 EC proposal pending. The author argues that, because the Spanish Constitution does not have clauses of intangibility, and even exist, the Constitutional Court it is just possible constitutional conformy of parliamentary acts of preparation of constitutional reform pursuant to article 23(2) EC. Although a bypothetical Declaration of invalidity of such acts for infringement of that article would not extend to the reform. Also notes the author that the Constitutional Court was admissible the demand and resolve it by a judgment.

RESUMEN: En este artículo su autor analiza el ATC 9/2012 que inadmitió a trámite el recurso de amparo interpuesto por varios parlamentarios contra las resoluciones y acuerdos de la Mesa del Congreso de los Diputados que dieron trámite a la proposición de reforma del artículo 135 CE. El autor sostiene que, dado que la Constitución española no posee cláusulas de intangibilidad, e incluso existiendo, al Tribunal Constitucional tan sólo le es posible juzgar la conformidad constitucional de los actos parlamentarios de elaboración de la reforma constitucional con lo dispuesto en el artículo 23.2 CE; 
aunque la hipotética declaración de nulidad de dichos actos por vulneración de dicho artículo no se extendería a la reforma misma. Señala también el autor que el Tribunal Constitucional debió admitir a trámite el recurso de amparo y resolverlo mediante Sentencia.

KEY WORDS: Constitutional amending, control of constitutionality of constitutional amending, constitutional theory

Palabras Clave: Reforma de la constitución, control de constitucionalidad de la reforma constitucional, teoría de la constitución

FECHA DE RECEPCIÓN: 15.06.202 FECHA DE ACEPTACIÓN: 19.07.2012

UNED. Teoría y Realidad Constitucional, núm. 30, 2012, pp. 483-498. 